\title{
PENGARUH FINANCIAL ATTITUDE, FINANCIAL BEHAVIOR, DAN FINANCIAL KNOWLEDGE TERHADAP FINANCIAL LITERACY PENGGUNA OVO DI JAKARTA BARAT
}

\author{
Jesslyn Adhitama Lauriady ${ }^{1}$, Hendra Wiyanto² \\ ${ }^{1}$ Program Studi Manajemen, Fakultas Ekonomi dan Bisnis, Universitas Tarumanagara \\ Email: jesslynadhitama@gmail.com \\ ${ }^{2}$ Program Studi Manajemen, Fakultas Ekonomi dan Bisnis, Universitas Tarumanagara* \\ Email: hendraw@fe.untar.ac.id \\ *Penulis Korespondensi
}

Masuk : 04-02-2021, revisi: 10-02-2021, diterima untuk diterbitkan : 02-03-2021

\begin{abstract}
ABSTRAK
Penelitian ini meneliti pengaruh dari sikap keuangan, perilaku keuangan dan pengetahuan keuangan terhadap literasi keuangan pengguna OVO di Jakarta Barat. Penelitian ini menggunakan responden sebanyak 235 responden pengguna OVO berdomisili di Jakarta Barat dan pengumpulan data menggunakan kuesioner. Desain penelitian ini menggunakan metode kuantitatif dengan pendekatan deskriptif dan teknik pengambilan sampel penelitian ini dengan teknik non probability sampling. Analisa data penelitian ini menggunakan Structural Equation Modelling (SEM) dengan software SmartPLS Versi 3.3.2 sebagai alat analisa data. Hasil yang di dapat dari penelitian ini adalah sikap keuangan berpengaruh signifikan terhadap literasi keuangan pengguna OVO, perilaku keuangan berpengaruh signifikan terhadap literasi keuangan pengguna OVO, pengetahuan keuangan berpengaruh signifikan terhadap literasi keuangan pengguna OVO di Jakarta Barat.
\end{abstract}

Kata Kunci: Sikap Keuangan, Perilaku Keuangan, Pengetahuan Keuangan, Literasi Keuangan

\section{ABSTRACT}

This study examines the effect of financial attitude, financial behavior, and financial knowlegde on financial literacy towards OVO users in West Jakarta. This study used 235 respondents of OVO users located in West Jakarta and collect data using a questionnaire. The design of this study uses a quantitative method with a descriptive approach and the sampling technique of this study is a non-probability sampling method. Analysis of the data of this study uses Structural Equation Modeling (SEM) with SmartPLS software Version 3.3.2 as a data analysis tool. The results obtained from this study are that financial attitude has a significant effect on the financial literacy of OVO users, financial behavior has a significant effect on the financial literacy of OVO users, and financial knowledge has a significant effect on the financial literacy of OVO users in West Jakarta.

Keywords: Financial Attitude, Financial Behavior, Financial Knowledge, Financial Literacy

\section{PENDAHULUAN}

\section{Latar Belakang}

Pada zaman sekarang ini, internet dan penggunaannya dalam kehidupan kita sehari-hari sudah tidak terpisahkan lagi. Seiring dengan kenaikan pengguna internet di Indonesia, maka masyarakatpun beralih menggunakan internet untuk melakukan segala sesuatu. dalam hal ini Asia Tenggara, termasuk Indonesia, membuat semua industri dan aktivitas menjadi daring, termasuk melakukan transaksi dan belanja. Didorong dengan demografi penduduk dan kemampuan belanja yang semakin besar dan mudahnya akses internet, belanja online pun semakin digemari masyarakat sehingga kedua belah pihak mendapatkan nilai dalam mencapai tujuannya masing-masing. 
Pesatnya perkembangan teknologi keuangan dan uang elektronik tidak bisa terlepas dari inovasi sistem berbasis teknologi yang terus mengusik sektor perbankan dan jasa keuangan (Hung \& Luo, 2016). Perkembangan teknologi yang semakin canggih menjadikan seluruh kegiatan seharihari juga semakin mudah, termasuk dalam hal bertransaksi dan menyumbang hadirnya teknologi keuangan (financial technology) atau disebut juga dengan uang elektronik atau dompet digital untuk mempermudah instrumen keuangan.

Inovasi ini telah menghasilkan perubahan struktur yang berdampak pada peningkatan efisiensi, penurunan biaya (cost reduction) serta koordinasi yang terbukti lebih efektif, kemudahan bertransaksi dan transportasi, sehingga dapat disimpulkan uang elektronik atau dompet digital akan semakin banyak digunakan dalam berbagai sektor. Dalam penelitian ini akan membahas dompet digital OVO sebagai objek penelitian dan juga sebagai salah satu aplikasi pelopor dalam dunia dompet digital di Indonesia.

Dengan demikian, perkembangan uang elektronik di Indonesia menandakan bahwa masyarakat sudah lebih sadar dalam memilih produk yang sama dengan harga terbaik karena banyak promo dan diskon agar pengguna uang elektronik terus bertambah. Hal ini berkaitan erat dengan tingkat literasi keuangan (financial literacy) masyarakat. Individu yang melek finansial akan membuat keputusan keuangan dan meminimalkan risiko disesatkan dalam berbagai masalah keuangan (Beal \& Delpachitra, 2003).

Menurut De Bassa Scheresberg (2013) orang dengan tingkat financial literacy yang tinggi akan lebih percaya diri dalam membuat keputusan keuangan pribadi dan sesuai dengan hasil moneter mereka dibandingkan dengan mereka yang memiliki tingkat financial literacy yang rendah, cenderung untuk berhutang dan membatasi keputusan keuangan. Pada penelitian ini, akan dibahas mengenai pengaruh financial attitude, financial behavior, financial knowledge terhadap financial literacy pengguna OVO di Jakarta Barat.

Financial Attitude (sikap keuangan) dapat diartikan sebagai sikap individu dalam memandang dan memahami keuangan. Sikap keuangan ini terbentuk dari perilaku individu dalam membuat keputusan keuangan dan kemudian sikap ini lambat laun dapat mengakar melalui keyakinan seseorang dalam mengelola keuangan (Ajzen, 1991).

Financial Behavior (perilaku keuangan) adalah perilaku yang memiliki keterkaitan dalam pengelolaan keuangan serta pengambilan keputusan keuangan, seperti membayar tagihan tepat waktu atau lebih awal, membuat perencanaan keuangan, dan menabung secara rutin dari pendapatan per bulan (Bhushan \& Medury, 2014; Kalekye \& Memba, 2015).

Financial Knowledge (Pengetahuan keuangan) adalah kemampuan akan penguasaan tentang keuangan (Kholilah \& Iramani, 2013).

Financial Literacy (literasi keuangan) adalah sebuah kombinasi akan kepekaan, pengetahuan, kemampuan, sikap dan perilaku untuk membentuk pengambilan keputusan keuangan dan dapat mencapai kesejahteraan finansial individu pada akhirnya. (Atkinson \& Messy, 2011).

\section{Kajian teori}

Penelitian ini mengacu kepada Theory of Planned Behavior atau Teori Perilaku Terencana yang dikembangkan oleh Ajzen (1991). Teori ini memberikan gambaran akan perilaku individu yang dipengaruhi oleh faktor-faktor, yaitu sikap terhadap perilaku (Attitudes towards Behavior), 
norma subjektif (Subjective Norms), persepsi kontrol perilaku (Perceived Control Behavior), dan intensi (Intentions). Kontrol perilaku menjelaskan bahwa individu dapat melakukan suatu hal dikarenakan keyakinan akan kemampuan individu dalam melakukan sesuatu (Ajzen, 1991).

Financial Attitude merupakan merupakan kemampuan seseorang dalam merencanakan dan menghemat uang di masa yang akan datang sehingga tidak menjadi sumber kecemasan atau rasa takut terhadap uang (Atkinson \& Messy, 2012).

Financial Behavior adalah perilaku manusia yang berkaitan dengan pengambilan keputusan dan pengelolaan keuangan seperti menyusun anggaran, membayar tagihan dengan efektif dan efisien, dan kebiasaan menabung teratur merupakan perilaku keuangan (Bhushan \& Medury, 2014).

Financial Knowledge atau pengetahuan keuangan dikatakan sebagai pengetahuan akan mengelola keuangan dalam pengambilan keputusan keuangan (Chen \& Volpe, 2008).

Financial Literacy atau literasi keuangan adalah kemampuan untuk membuat penilaian berdasarkan informasi dan digunakan untuk mengambil keputusan keuangan secara efektif mengenai penggunaan dan pengelolaannya (Noctor et al. 1992). Individu yang melek akan keuangan lebih cenderung untuk membuat keputusan keuangan dan meminimalkan risiko mengalami masalah keuangan (Beal dan Delpachitra, 2003).

\section{Kaitan antara Financial Attitude dan Financial Literacy.}

Menurut OECD (2013), selain pengetahuan dan kesadaran akan keuangan, sikap dan perilaku keuangan juga sangat perlu untuk diperhatikan agar financial literacy masyarakat meningkat. Hal ini berarti bahwa financial literacy dan financial attitude memiliki relasi yang positif, hal ini dikarenakan individu yang memiliki financial attitude yang tinggi cenderung memiliki financial literacy yang tinggi juga sehingga cerdas dalam menggunakan keuangan.

\section{Kaitan antara Financial Behavior dan Financial Literacy.}

Financial behavior sangat penting dan merupakan komponen yang fundamental dari financial literacy (OECD, 2013). Cara seseorang berperilaku akan memengaruhi kesejahteraan keuangannya secara signifikan. financial behavior yang positif berupa perencanaan keuangan yang baik, termasuk mengatur pengeluaran dan menjaga stabilitas keuangan mampu meningkatkan financial literacy individu (Atkinson \& Messy, 2012). De Bassa Scheresberg (2013) menyatakan bahwa terdapat pengaruh antar financial behavior dengan financial literacy, dimana financial behavior merupakan dimensi dari financial literacy.

\section{Kaitan antara Financial Knowledge dan Financial Literacy.}

Terdapat sebuah asosiasi yang positif antara tingkat financial literacy dengan tingkat pendidikan dan tingkat pendapatan (Hilgert et al, 2002; Perry and Morris, 2005). Perry \& Morris (2005) menyatakan bahwa individu yang memiliki tingkat financial literacy yang lebih baik lebih memungkinkan untuk menabung, menganggarkan serta merencanakan keuangan masa depan. Sebaliknya, tingkat financial knowledge yang rendah memiliki konsekuensi dalam keuangan pribadi di masa depan (Hasler \& Lusardi, 2017).

Berdasarkan uraian kaitan antar variabel di atas, maka kerangka pemikiran yang digunakan dalam penelitian ini adalah sebagai berikut: 


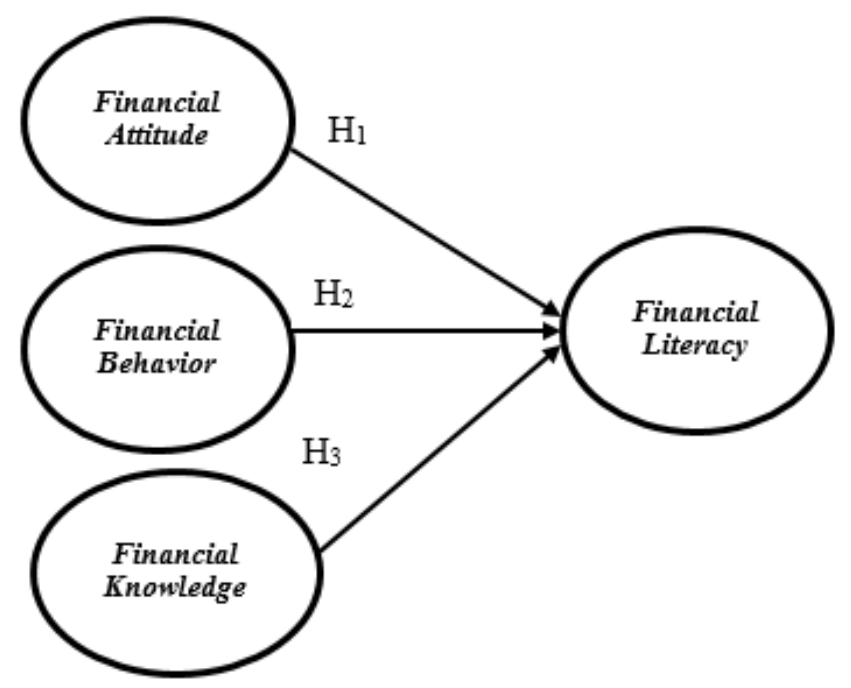

Gambar 1. Kerangka pemikiran

\section{METODE PENELITIAN}

Penelitian ini menggunakan jenis penelitian deskriptif (descriptive research) karena tujuan dari penelitian ini adalah untuk menjelaskan atau mendeskripsikan pengaruh suatu variabel terhadap variabel lainnya. Teknik analisis yang digunakan adalah model persamaan struktural atau Structural Equation Modelling (SEM). Teknik analisis ini meliputi outer model analysis berupa uji validitas dan reliabilitas, dan inner model analysis berupa uji koefisien determinasi, uji hipotesis menggunakan bootstrapping dan uji Goodness Fit. Metode kuantitatif digunakan untuk mengukur hasil yang objektif menggunakan analisis statistik dengan menggunakan data angka.

Pada penelitian ini menggunakan non-probability sampling dengan teknik purposive sampling sebagai teknik pemilihan sampel agar pengumpulan data dapat dilakukan sesuai dengan kriteria penelitian ini. Penelitian ini melibatkan 235 responden yang penyebaran kuesionernya dilakukan melalui Google form. Skala yang digunakan untuk mengukur indikator variabel dalam penelitian ini adalah skala Likert dengan angka 1 yang menunjukkan sangat tidak setuju sampai angka 5 yang menunjukkan sangat setuju.

\section{HASIL DAN PEMBAHASAN}

Subjek penelitian ini adalah pengguna OVO yang berdomisili di Jakarta Barat sebanyak 235 responden. Responden ini dikelompokkan berdasarkan domisili, jenis kelamin, usia, pendidikan terakhir, dan pekerjaan. Dari 249 responden, sebanyak 235 responden atau $94 \%$ menjawab ya menggunakan OVO dan berdomisili di Jakarta Barat, sedangkan 6\% sisanya tidak menggunakan OVO dan tidak berdomisili di Jakarta Barat. Berdasarkan jenis kelamin, responden yang berjenis kelamin perempuan adalah sebanyak 156 responden $(66,38 \%)$ dan jumlah responden yang berjenis kelamin laki-laki sebanyak 79 responden $(33,62 \%)$. Berdasarkan usia, sebanyak 27 responden berusia kurang dari 20 tahun $(11,48 \%)$, 191 responden berusia antara 20-30 tahun $(81,28 \%), 6$ responden berusia antara 31-40 tahun (2,56\%) dan 11 responden berusia lebih dari 40 tahun $(4,68 \%)$. Berdasarkan pendidikan terakhir, diperoleh bahwa responden yang tingkat pendidikan terakhir SMA/SMK sebanyak 147 responden $(62,55 \%)$, tingkat pendidikan terakhir D3 sebanyak 5 responden $(2,13 \%)$, tingkat pendidikan terakhir S1 sebanyak 78 responden $(33,19 \%)$, tingkat pendidikan terakhir S2 sebanyak 4 responden $(1,70 \%)$ dan tingkat pendidikan terakhir S3 sebanyak 1 responden $(0,43 \%)$. Berdasarkan pekerjaan, sebanyak 170 responden $(72,34 \%)$ berstatus pelajar/mahasiswa, sebanyak 47 responden (20\%) berstatus karyawan/karyawati, sebanyak 4 responden $(1,70 \%)$ merupakan ibu rumah tangga, sebanyak 2 
responden $(0,85 \%)$ adalah pegawai negeri, sebanyak 11 responden $(4,68 \%)$ berwirausaha dan 1 responden $(0,42 \%)$ bekerja lainnya dari yang tertera.

Data pada penelitian ini telah memenuhi syarat kelayakan uji validitas dan reliabilitas dengan uji outer model analysis nilai Average Variance Extracted (AVE) seluruh variabel lebih besar dari 0,50, nilai uji composite reliability penelitian ini lebih besar dari 0,60 yang berarti memenuhi syarat pada uji reliabilitas yang diukur dengan composite reliability, dan pada uji Cronbach's Alpha semua variabel telah memenuhi syarat dengan nilai diatas 0,60 .

Tabel 1. Hasil Uji Validitas dan Reliabilitas

\begin{tabular}{|c|c|c|c|}
\hline Variabel & AVE & Composite Reliability & Cronbach's Alpha \\
\hline Financial Attitude & $\mathbf{0 , 5 6 2}$ & $\mathbf{0 , 8 8 4}$ & $\mathbf{0 , 8 4 2}$ \\
\hline Financial Behavior & $\mathbf{0 , 5 0 4}$ & $\mathbf{0 , 8 0 2}$ & $\mathbf{0 , 6 7 8}$ \\
\hline Financial Knowledge & $\mathbf{0 , 5 6 0}$ & $\mathbf{0 , 8 3 3}$ & $\mathbf{0 , 7 3 4}$ \\
\hline Financial Literacy & $\mathbf{0 , 5 6 2}$ & $\mathbf{0 , 8 8 4}$ & $\mathbf{0 , 8 4 1}$ \\
\hline
\end{tabular}

Maka dengan demikian data dalam penelitian ini terbukti valid dan reliabel sehingga dapat digunakan untuk analisa tingkat lanjut. Sedangkan tabel dibawah ini menunjukkan hasil uji cross loadings setiap variabel lebih besar dari variabel lainnya sehingga memperkuat validitas data penelitian ini.

Tabel 2. Hasil Uji Cross Loadings

\begin{tabular}{|l|r|r|r|r|}
\hline & Financial Attitude & Financial Behavior & Financial Knowledge & \multicolumn{1}{c|}{ Financial Literacy } \\
\hline FA1 & 0,672 & 0,445 & 0,516 & 0,499 \\
\hline FA2 & 0,821 & 0,570 & 0,583 & 0,660 \\
\hline FA3 & 0,787 & 0,541 & 0,566 & 0,600 \\
\hline FA4 & 0,809 & 0,582 & 0,632 & 0,670 \\
\hline FA5 & 0,726 & 0,437 & 0,483 & 0,540 \\
\hline FA6 & 0,666 & 0,513 & 0,448 & 0,507 \\
\hline FB1 & 0,609 & 0,768 & 0,601 & 0,597 \\
\hline FB2 & 0,461 & 0,716 & 0,494 & 0,469 \\
\hline FB4 & 0,429 & 0,676 & 0,315 & 0,368 \\
\hline FB6 & 0,421 & 0,674 & 0,348 & 0,412 \\
\hline FK1 & 0,416 & 0,400 & 0,570 & 0,667 \\
\hline FK2 & 0,647 & 0,506 & 0,826 & 0,749 \\
\hline FK4 & 0,572 & 0,581 & 0,823 & 0,536 \\
\hline FK5 & 0,503 & 0,412 & 0,744 & 0,572 \\
\hline FL1 & 0,421 & 0,435 & 0,418 & 0,712 \\
\hline FL2 & 0,606 & 0,497 & 0,564 & 0,768 \\
\hline FL3 & 0,671 & 0,587 & 0,626 & 0,789 \\
\hline FL4 & 0,530 & 0,559 & 0,671 & 0,843 \\
\hline FL5 & 0,645 & 0,469 & 0,672 & 0,785 \\
\hline FL6 & 0,599 & 0,456 & 0,663 & \\
\hline
\end{tabular}

Kemudian dalam uji inner model analysis, dilakukan uji koefisien determinasi $\left(\mathrm{R}_{2}\right)$, Uji hipotesis dan uji Goodness to Fit (GoF). Hasil dari uji koefisien determinasi disajikan dalam tabel sebagai berikut:

Tabel 3. Hasil Uji Koefisien Determinasi

\begin{tabular}{|c|c|}
\hline & $R$-Square \\
\hline Financial Literacy & 0,743 \\
\hline
\end{tabular}


Dari Tabel 3 diatas menunjukkan bahwa hasil koefisien determinasi sebesar 0,743 atau 74,3\% dari variabel dependen yakni financial literacy dapat dijelaskan oleh variabel independen yakni financial attitude, financial behavior, dan financial knowledge. Koefisien determinasi merupakan ukuran dari akurasi prediksi sebuah model penelitian, dengan kata lain koefisien determinasi bertujuan untuk melihat kontribusi variabel independen terhadap variabel dependen.

Kemudian pada pengujian Goodness to Fit atau GoF yang dilakukan secara manual, maka dapat disimpulkan bahwa model penelitian ini memiliki tingkat kecocokan yang tergolong besar (GoF Large) sebesar 0,5495.

Tabel 4. Hasil Pengujian Hipotesis menggunakan Bootstrapping

\begin{tabular}{|c|c|c|}
\hline Variabel & t-statistic & $\boldsymbol{p}$-value \\
\hline Financial Attitude $\rightarrow$ Financial Literacy & 5,887 & 0,000 \\
\hline Financial Behavior $\rightarrow$ Financial Literacy & 1,984 & 0,048 \\
\hline Financial Knowledge $\rightarrow$ Financial Literacy & 10,233 & 0,000 \\
\hline
\end{tabular}

Berdasarkan hasil pengujian hipotesis menggunakan bootstrapping financial attitude terhadap financial literacy, dapat dilihat bahwa nilai t-statistic memperoleh nilai 5,887 dan nilai $p$-value sebesar 0.000 yang berarti nilai tersebut kurang dari 0.05. Dari nilai tersebut dapat dikatakan bahwa $\mathrm{H}_{1}$ bahwa terdapat pengaruh financial attitude terhadap financial literacy tidak ditolak.

Berdasarkan hasil pengujian financial behavior terhadap financial literacy, nilai $t$-statistic sebesar 1,984 dan nilai p-value sebesar 0.048 yang kurang dari 0.05. Dari nilai tersebut dapat dikatakan bahwa $\mathrm{H}_{2}$ bahwa terdapat pengaruh financial behavior terhadap financial literacy tidak ditolak.

Kemudian berdasarkan hasil pengujian financial knowledge terhadap financial literacy dengan dapat dilihat bahwa nilai $t$-statistic menghasilkan nilai 10,233 dan nilai $p$-value sebesar 0.000 yang dimana nilainya kurang dari 0.05 . Dari nilai tersebut dapat dikatakan bahwa $\mathrm{H}_{3}$ terdapat pengaruh financial knowledge terhadap financial literacy tidak ditolak.

\section{Diskusi}

Berdasarkan hasil diatas, maka dapat disimpulkan bahwa penelitian ini valid dan reliabel. Walaupun penelitian ini memiliki kekurangan dan keterbatasan, baik dari lingkup penelitian maupun subjek penelitian, Penelitian ini sesuai dengan penelitian yang dilakukan oleh (Garg dan Singh, 2018) yang menyatakan bahwa terdapat pengaruh antara financial attitude, financial behavior, dan financial knowledge terhadap financial literacy generasi muda di dunia, serta penelitian yang dilakukan oleh (Kamini Rai, Shikha Dua \& Miklesh Yadav, 2019) yang dalam hal ini subjeknya adalah wanita pekerja di India untuk mengetahui pengaruh financial attitude, financial behavior dan financial knowledge terhadap financial literacy.

Adapun hasil yang didapatkan oleh penelitian ini juga sesuai dengan hasil penelitian yang dilakukan oleh (Bhushan dan Medury, 2014) yang hasilnya adalah terdapat hubungan antara financial attitude, financial behavior dan financial knowledge terhadap financial literacy terhadap orang-orang yang telah bekerja di Himachal Pradesh, India. Untuk meningkatkan financial literacy masyarakat tidak cukup hanya dengan pengetahuan keuangan namun juga harus diimbangi dengan sikap keuangan dan perilaku keuangan. 
Berdasarkan pengujian hipotesis yang telah dilakukan di atas dan juga dari beberapa contoh penelitian terdahulu tersebut, maka penelitian ini membuktikan bahwa financial attitude, financial behavior dan financial knowledge berpengaruh positif terhadap financial literacy.

\section{KESIMPULAN DAN SARAN}

Financial attitude memiliki pengaruh yang positif terhadap financial literacy pengguna OVO di Jakarta Barat, hal ini menjelaskan bahwa sikap keuangan yang bijak berpengaruh terhadap tingkat literasi keuangan pengguna dompet digital, dikarenakan mudahnya akses untuk bertransaksi sehingga dibutuhkan sikap keuangan yang baik agar dapat menggunakan dan memanfaatkan dompet digital dengan bijak. Selanjutnya, financial behavior berpengaruh positif terhadap financial literacy pada pengguna OVO di Jakarta Barat. Hal ini menjelaskan bahwa perilaku keuangan seperti menabung, perencanaan keuangan yang baik, mengatur pengeluaran dan menjaga stabilitas keuangan mampu meningkatkan literasi keuangan pengguna dompet digital sehingga adanya dompet digital mampu membantu seseorang dalam mengelola keuangannya. Kemudian, financial knowledge berpengaruh positif terhadap financial literacy. Hal ini menerangkan bahwa memiliki pengetahuan keuangan yang memadai akan meningkatkan literasi keuangan seseorang dengan memahami, menganalisis, memiliki pengertian dasar sehingga mampu mengambil keputusan keuangan didalam dompet digital dengan lebih matang, mengingat fitur dan promo yang ditawarkan dompet digital beragam sehingga perlu dipahami.

Adapun saran untuk perusahaan agar tetap meningkatkan kinerja sistem dan lebih banyak bekerjasama dengan merchant diberbagai sektor sehingga semakin memudahkan pengguna. Untuk penelitian selanjutnya, diharapkan dapat menambah indikator untuk mendukung setiap variabel serta memperluas lingkup subjek penelitian ke berbagai daerah selain Jakarta Barat sehingga hasil yang didapatkan lebih baik dari penelitian-penelitian sebelumnya.

\section{REFERENSI}

Ajzen, I. (1991). The Theory of Planned Behavior. In Handbook of Theories of Social Psychology. Volume 1 (Vol. 211, pp. 438-459). SAGE Publications Ltd.

Atkinson, A., \& Messy, F. (2012). Measuring Financial Literacy: Results Of The OECD/ International Network On Financial Education (Infe) Pilot Study. Paris: Organisation For Economic Cooperation And Development.

Bhushan, P \& Medury, Y. (2014). An Empirical Analysis of Inter Linkages Between Financial Attitudes, Financial Behaviour and Financial Knowledge of Salaried Individuals. Indian Journal of Commerce and Management Studies, Nasik Vol. 5, Iss. 3, 58-64.

Chen, H. \& Volpe, R.P. (2002), "Gender differences in personal financial literacy among college students", Financial Services Review, Vol. 11 No. 3, pp. 289-307.

Garg, N., \& Singh, S. (2018). Financial Literacy Among Youth. International 100 Journal of Social Economics, 45(1), 173-186.

Kalekye, P. \& Memba, F. (2015). The role of financial literacy on the profitability of women owned enterprises in Kitui Town, Kitui Country, Kenya. International Journal of Science \& Research.

Kholilah, N. Al, \& Iramani, R. (2013). Studi Financial Management Behavior Pada Masyarakat Surabaya. Journal of Business and Banking, 3(1), 69.

Lusardi, A., Mitchell, O., \& Curto, V. (2010). Financial Literacy Among The Young. The Journal of Consumer Affairs, Madison Vol. 44,Iss. 2, 358

Rai, dkk. (2019). Association of Financial Attitude, Financial Behaviour and Financial Knowledge Towards Financial Literacy: A Structural Equation Modeling Approach." FIIB Business Review 8(1):51-60. 
Scheresberg, C. de B. (2013). Financial literacy and financial behavior among young adults: Evidence and Implications. Numeracy, 6(2).

Perry, V. \& Morris, D. (2015). "The Role of Self-Perception, Knowledge, and Income in Explaining Consumer Financial Behavior." The Journal of Consumer Affairs, Vol. 39, No. 2. 